\title{
READERS' VIEWS
}

\section{Dear Editor}

Your contributor Dr Michael Christie who wrote the article entitled "What is a part-Aborigine?" in your February/March 1986 issue, is obviously in sympathy with his subjects and prepared to castigate the "white" teachers whom he sees as unsympathetic. However, he does not seem to have addressed the question that he uses for his title, and has wandered too far into the details of Aboriginal cultural activities and beliefs.

There are increasing numbers of PART-ABORIGINES in our society and his dislike of the term does nothing to reduce their numbers. I will define a PART-ABORIGINE as a person whose ancestors include both Europeans and Aboriginal Australians in their number. While I agree that in all population groups ( $I$ dislike the word "races") there can be a wide range of physical types and an even wider range of mental attitudes, beliefs, mores, etc., yet there are clearly recognisable individuals of Euro/Australian ancestry.

The unfortunate fact is that, because there are payments and priorities, positive discriminations, in favour of being Aboriginal, the PART-ABORIGINES are induced to stress their Aboriginality and deny the non-Aboriginal part of their background. It is unfortunate because, although their Aboriginal background may lead to emotional stability and contentment, they have to exist and "progress" (?) in the confused world of the more technically advanced nations, and the Aboriginal ways are not conducive to this.

I think that the final sentence does not do justice to the remainder of the article. The juxtaposition of "part Aborigines" and "part human beings" is an emotional and illogical tactic. Indeed Aborigines and all people are "human beings"; it is a truism, but carries a wealth of connotations. Their humanity is not questioned, although $I$ wonder if $D r$ Christie is still carrying a burden of guilt handed down from his ancestors.

What is questionable, however, is the argument implicit in the article, that the Aboriginal part of their inheritance is more important (however you choose to define "importance") than their European inheritance and, to make my own opinion very clear, I feel that only emotional arguments favour the proposition whilst practical considerations do not. 
Whilst I sympathise with the confusion in the minds of the Australian Aborigines, part or "full-blood", I am not convinced that Dr Christie will do more than foster discontent and a sense of grievance in those people he wishes to assist.

-sgd- Arthur Davies

Principal

Mullewa District High School

MULLEWA W.A. 6630

\section{Dear Editor}

Eve Fesl's suggestions regarding the use of Electronic Media, (The Aboriginal Child at School, Vol.13:5, October/November, 1985) in particular her analogy to the Welsh use of media, to promote Aboriginal language maintenance, invite a reply.

The entire Welsh exercise proceeds from the singular fact that the Welsh agree to employ a single dialect as the language to be maintained. This permits the "high quality" programming Ms. Fesl recommends and allows for an analogy to $0 / 28$ production which reaches audiences of hundreds of thousands of ethnic viewers/speakers. Where so many people speak a language it becomes economically feasible to produce quality programming as well as to access expensive transmission networks, such as satellites. When languages have only a few thousand speakers at most, expensive production and transmission is uneconomic and therefore unlikely.

The most critical point to raise with Aboriginal language maintenance is that it is not one, but many languages we wish to maintain. For example, in the Central Aussat zone, at least 22 Aboriginal languages are still spoken. This presents a fundamental problem if we were to adopt the $0-28$ model. Each language could be featured for only $1 / 22$ of the broadcast day, and if English translation were required, for only 1/44. This would mean that each language could be spoken less than $1 / 2$ hour during each day's programming. It is difficult to call this functional language maintenance.

A number of remote communities are now experimenting with local production and transmission of programs in traditional languages. These programs could not be called "high quality" in the European sense of the Welsh productions. They must be made 
cheaply, on available home production equipment. But they are extremely popular and competitive with imported fare because they provide something that no high quality production house could: locally relevant content in local languages for a few hundred remote viewers.

Generally, the government seems more supportive of proposals such as MS Fesl's than remote communities' own expressed desires to produce and manage their own media locally. Considerable funds are being channelled into regional and national Aboriginal services, perhaps at the expense of local community stations. It may be that there is a covert "pan-Aboriginalisation" agenda here. Speaking of Aboriginal language in the singular, and designing or recommending production and broadcasting systems which can only carry one or a few languages would surely result in a levelling of linguistic diversity throughout Aboriginal Australia. Indeed, I am familiar with the position of some that for Aboriginal language to survive, standardisation of this type may be necessary. This position appears to be held by people in positions to be making decisions about Aboriginal media development, legislation and support. My only complaint here is that this position on a pan-Aboriginal language is never stated in the context of media recommendations which, I suspect, are designed to encourage just this.

I submit it would be more appropriate to spell out just what the options are, particularly to those people who now maintain their language and see it threatened by introduced electronic media:

either

$$
\begin{aligned}
& \text { "high quality programming produced at } \\
& \text { regional or urban production houses in } \\
& \text { one or a very few languages, }
\end{aligned}
$$

or

"home quality" programming locally produced within each language group.

What makes these options mutually exclusive is not only the very different kinds of funding required for each from what is proving to be a very small pie, but the very different ways the same technology must be used to support one or another system. I would welcome any contradictions which demonstrate how both objectives could be served.

-sgd- Eric Michaels

Research Fellow, Remote Television Project Australian Institute of Aboriginal Studies P O Box 553, Canberra City, ACT 2601 